\title{
Исследование диодов Шоттки на основе массива кремниевых волокон, полученных сухим криогенным травлением
}

\author{
(C) А.И. Баранов ${ }^{1,2}$, Д.А. Кудряшов ${ }^{1,2}$, А.В. Уваров ${ }^{1,2}$, И.А. Морозов ${ }^{1,2}$, К.Ю. Шугуров ${ }^{1}$, \\ А.А. Максимова ${ }^{1,2}$, Е.А. Вячеславова ${ }^{1,2}$, А.С. Гудовских ${ }^{1,2}$ \\ ${ }^{1}$ Санкт-Петербургский национальный исследовательский Академический университет им. Ж.И. Алфёрова РАН, \\ Санкт-Петербург, Россия \\ ${ }^{2}$ Санкт-Петербургский государственный электротехнический университет „ЛЭТИ“, Санкт-Петербург, Россия \\ E-mail: baranov_art@spbau.ru
}

Поступило в Редакцию 4 мая 2021 г.

В окончательной редакции 13 июня 2021 г.

Принято к публикации 16 июня 2021 г.

\begin{abstract}
Рассмотрены массивы кремниевых вертикально ориентированных волокон, полученных сухим криогенным травлением кремниевых подложек с концентрацией свободных электронов $n=10^{16}$ и $10^{17} \mathrm{~cm}^{-3}$, высотой $6 \mu \mathrm{m}$ и диаметром 1.7 и $1.2 \mu \mathrm{m}$ соответственно. Продемонстрировано, что напыление золота позволяет сформировать диод Шоттки с коэффициентом идеальности $1.1-1.3$ и высотой барьера $0.6-0.7 \mathrm{eV}$ при данных параметрах этих массивов. Показано, что экспериментальные кривые вольт-фарадных характеристик таких структур могут быть проанализированы с помощью модели, учитывающей вклад в емкость от всей поверхности волокон. Это позволило провести численную оценку профиля концентрации свободных носителей заряда именно в массиве волокон, что показало хорошее численное совпадение с уровнем легирования в исходных подложках.
\end{abstract}

Ключевые слова: кремниевые волокна, солнечный элемент, криогенное травление, вольт-фарадное профилирование.

DOI: 10.21883/PJTF.2021.18.51474.18855

На данный момент рекордный КПД 26.6\% в однопереходном солнечном элементе на подложках $\mathrm{Si}$ достигнут на гетеропереходе $a-\mathrm{Si}: \mathrm{H} / c-\mathrm{Si}[1]$, это значение близко к теоретическому пределу $\sim 30 \%$ согласно модели Шокли-Квиссера. Одним из подходов, направленных на развитие кремниевой фотовольтаики, является создание трехмерных структур, в частности, вертикально ориентированных кремниевых нановолокон (silicon nanowires, $\mathrm{SiNWs),} \mathrm{что} \mathrm{позволяет} \mathrm{достичь} \mathrm{большего} \mathrm{поглощения}$ солнечного излучения, чем в случае планарных слоев [2]. Однако при создании нановолокон методами VLS (vaporliquid-solid) и MACE (metal assisted chemical etching) образуются дефекты из-за используемых катализаторов золота и серебра $[3,4]$. Поэтому в настоящее время возрос интерес к методу сухого плазмохимического травления подложки $\mathrm{Si}$ при криогенных температурах менее $-100^{\circ} \mathrm{C}$ для создания массивов однородных SiNWs [5-7]. Ранее нами было показано, что наносферная литография и сухое плазмохимическое травление с индуктивносвязанной плазмой при криогенных температурах позволяют получить равномерный массив однородных $\mathrm{SiNWs}$

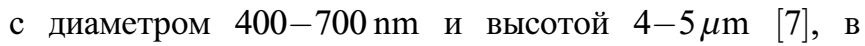
приповерхностной области которых образуются дефекты с небольшой концентрацией, которая уменьшается после обработки в КОН $[8,9]$. С другой стороны, имеется мало работ, посвященных исследованию вольт-фарадных характеристик $(C-V)$ на структурах именно с массивом нановолокон. Существуют только работы по изучению емкости единичного нановискера: исследованию его экс- периментальных $C-V$ характеристик [10] и их численному моделированию $[11,12]$. Поэтому в настоящей работе изучено поведение экспериментальных $C-V$-характеристик диодов Шоттки на массиве кремниевых волокон.

Были использованы подложки кремния Siltronix c $0.2 \Omega \cdot \mathrm{cm}\left(n=10^{16} \mathrm{~cm}^{-3}\right)$ и $0.06 \Omega \cdot \mathrm{cm}\left(n=10^{17} \mathrm{~cm}^{-3}\right)$. Формирование массива SiNWs было проведено по стандартной технологии [7]: плазмохимическое осаждение слоя $\mathrm{SiO}_{2}$ толщиной $400 \mathrm{~nm}$ в установке Oxford PlasmaLab System100, нанесение латексных сфер диаметром $2 \mu \mathrm{m}$ методом центрифугирования, уменьшение их диаметра до 1.3 и $1.8 \mu \mathrm{m}$ для подложек с 0.06 и $0.2 \Omega \cdot \mathrm{cm}$ соответственно сухим травлением в потоке $\mathrm{O}_{2}$ в установке Oxford Plasma Lab ICP 380, травление слоя $\mathrm{SiO}_{2}$ между сферами в потоке $\mathrm{CHF}_{3}$ до подложки кремния, травление $\mathrm{Si}$ в режиме индуктивно-связанной плазмы при $-140^{\circ} \mathrm{C}$ в потоке газов $\mathrm{SF}_{6} / \mathrm{O}_{2}$. В результате был получен равномерный массив однородных волокон высотой $6 \mu \mathrm{m}$ с диаметром 1.2 и $1.7 \mu \mathrm{m}$ для 0.06 и $0.2 \Omega \cdot \mathrm{cm}$ соответственно. На тыльную сторону подложки был осажден $n$ - $a$-Si:H $(5 \mathrm{~nm})$. Обе подложки с SiNWs были поделены на две части: первые половины остались исходными, а на вторые посредством центрифугирования $(800 \mathrm{rpm}, 1 \mathrm{~min})$ наносился слой фоторезиста SU-8 толщиной $580 \mathrm{~nm}$. Образцы отжигались в течение $1 \mathrm{~min}$ при температуре $95^{\circ} \mathrm{C}$ (soft bake) в духовом шкафу для удаления остатков растворителя из резиста, после чего проводилось экспонирование УФ-излучением $(365 \mathrm{~nm})$. 

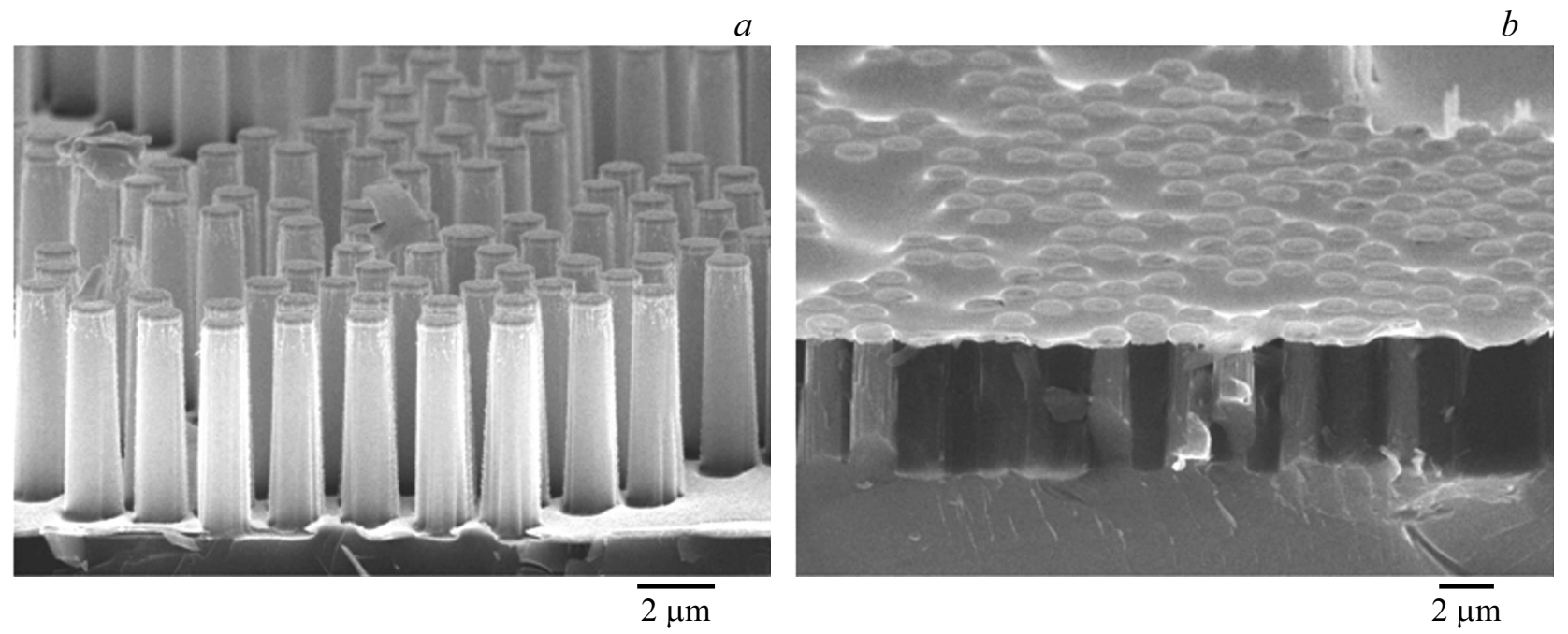

Pис. 1. Полученные методом растровой электронной микроскопии изображения исходного $(a)$ и заполненного SU-8 $(b)$ массива кремниевых волокон с напыленным золотом.

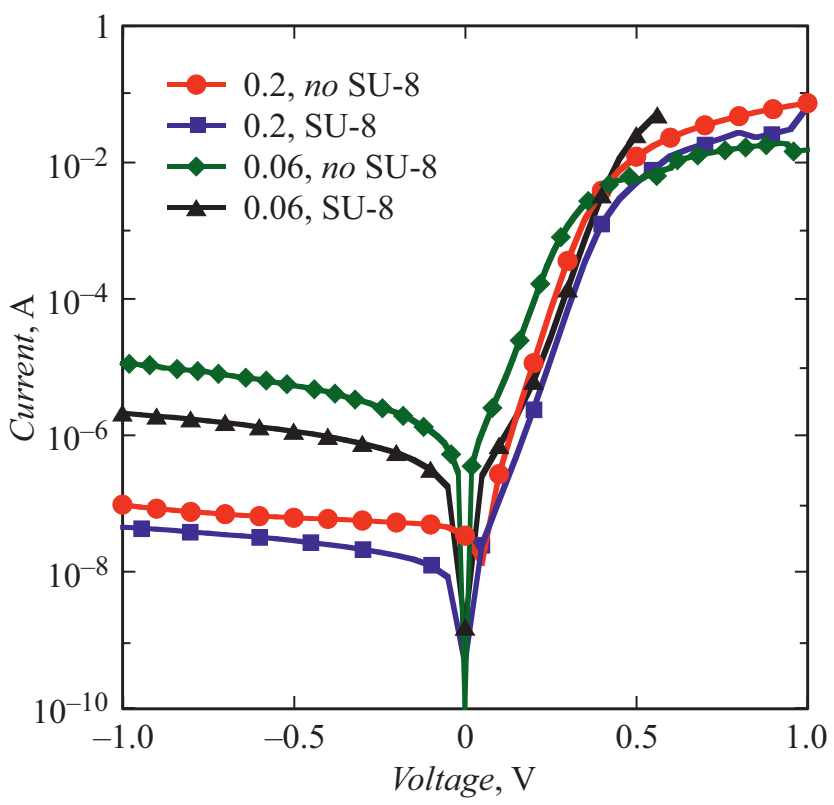

Рис. 2. Вольт-амперные характеристики массива волокон с напыленным золотом, измеренные в темноте.

Для отверждения фоторезиста образцы отжигались в течение $10 \mathrm{~min}$ при $170^{\circ} \mathrm{C}$ (hard bake). Далее они обрабатывались $3 \mathrm{~min}$ в кислородной плазме $(60 \mathrm{sccm}, 400 \mathrm{~W})$ в установке PiNK Plasma system V15-G. В результате SiNWs были очищены от SU-8 на $170 \mathrm{~nm}$ относительно вершин волокон. На все образцы через маску с отверстиями диаметром $1 \mathrm{~mm}$ на лицевую сторону было напылено золото толщиной $200 \mathrm{~nm}$ для формирования барьера Шоттки, а на тыльную сторону - сплошной слой серебра для создания омического контакта (рис. 1).

Вольт-амперные характеристики образцов, измеренные в темноте с помощью источника-измерителя
Keithley 2400, представлены на рис. 2. Зависимости для всех образцов соответствуют поведению, характерному для диода Шоттки: низкий ток при обратном напряжении смещения во всем диапазоне, экспоненциальный рост при прямом напряжении смещения до $+0.8 \mathrm{~V}$ с последующим насыщением при больших значениях. Согласно анализу кривых, расчетный коэффициент идеальности $N$ для всех образцов составляет от 1.1 до 1.6, причем он равен 1.14 для $n$-Si с $0.2 \Omega \cdot \mathrm{cm}$ без заливки SU-8, что свидетельствует о высоком качестве полученного массива SiNWs, а именно интерфейса $\mathrm{Au} / n-\mathrm{Si}$ (в отличие от 1.37 для $n-\mathrm{Si} \mathrm{c} 0.06 \Omega \cdot \mathrm{cm})$. Тем не менее коэффициент $N$ увеличивается на $10 \%$ для структур на обоих типах подложек после заливки по сравнению со значениями для исходных, что может свидетельствовать об ухудшении качества интерфейса $\mathrm{Au} / n-\mathrm{Si}$ после постростовой процедуры.

$C-V$-характеристики, полученные на $R L C$-измерителе Keysight E4980A-001 при $100 \mathrm{kHz}$ и $300 \mathrm{~K}$, показаны на рис. 3. Значение емкости всех структур уменьшается с увеличением амплитуды смещения, что связано с увеличением толщины области пространственного заряда (ОП3) в Si. B структурах с SU-8 значения емкости идентичны при варьировании напряжения как от 0 до $-2 \mathrm{~V}$, так и в обратную сторону, что означает отсутствие перезарядки на границе диэлектрик/кремний. Поэтому образцы с SU-8 будем рассматривать как массив параллельных SiNWs, металлический контакт к которым сформирован только на верхней грани, и полная емкость равна произведению емкости одного SiNW на их количество в единице площади. Согласно снимкам растровой электронной и оптической микроскопии, достигнута плотная упаковка при центрифугировании латексных сфер, что означает покрытие 70\% подложки, поэтому 


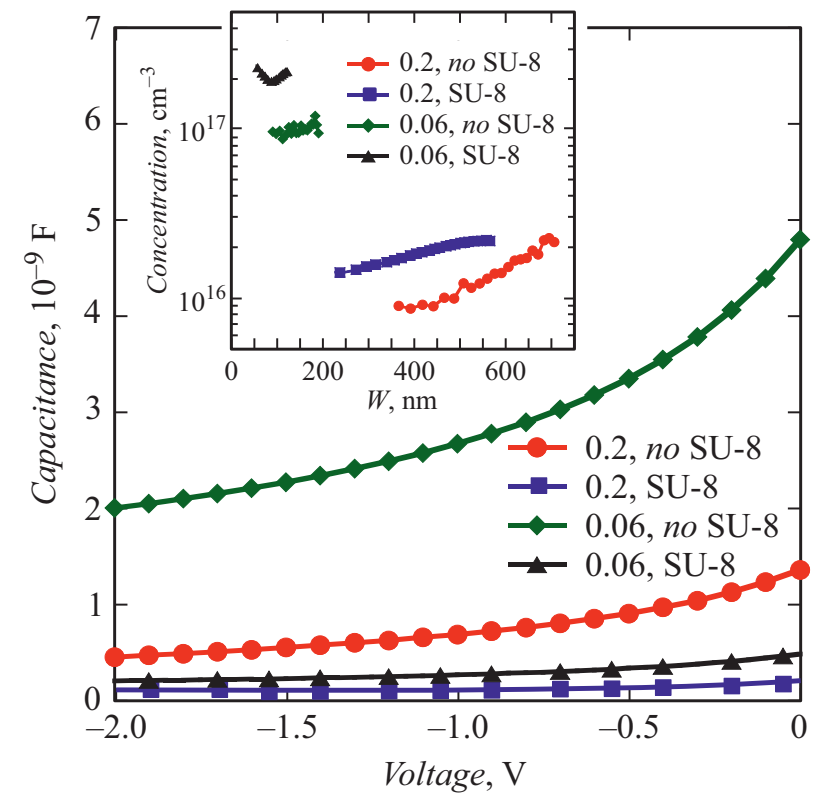

Рис. 3. Вольт-фарадные характеристики массивов волокон с напыленным золотом. На вставке - расчетные профили концентрации свободных носителей заряда.

площадь всех верхних граней определяется как

$$
S_{\mathrm{NW} \text { top }}=0.7 S_{M e} R_{\mathrm{NW}}^{2} / R_{\text {sphere }}^{2}
$$

где $R_{\mathrm{NW}}-$ радиус полученных волокон, $R_{\text {sphere }}-$ радиус исходных латексных сфер до уменьшения (в этой работе он равен $2 \mu \mathrm{m})$, а $S_{M e}$ - площадь металлического контакта. В результате она равна 25 и 50\% от

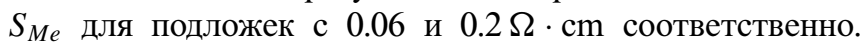
Поскольку при увеличении амплитуды обратного напряжения ОПЗ расширяется только к низу волокна вдоль его оси, применимо приближение плоского конденсатора для расчета толщины ОПЗ и профиля концентрации свободных носителей заряда (вставка на рис. 3). Расчетный профиль концентрации имеет равномерный характер вдоль SiNWs в подложке с $0.2 \Omega \cdot \mathrm{cm}$ и отвечает концентрации $1.2 \cdot 10^{16} \mathrm{~cm}^{-3}$, что согласуется между собой. Так как SiNWs вскрыты на $170 \mathrm{~nm}$ и золото напылено на всю вскрытую часть, для концентрации $1 \cdot 10^{16} \mathrm{~cm}^{-3}$ весь массив SiNWs над поверхностью SU-8 обеднен полностью уже при $0 \mathrm{~V}$. Однако для концентрации $1 \cdot 10^{17} \mathrm{~cm}^{-3}$ толщина ОПЗ менее $100 \mathrm{~nm}$, поэтому емкость будет равна сумме двух параллельных емкостей: $C_{\mathrm{NWtop}}$, формируемой под контактом к верхней грани SiNWs, и $C_{\mathrm{NW}}$ side, формируемой под боковой поверхностью SiNWs. Для образца с SU-8 площадь под верхней гранью в 5 раз больше площади под боковой поверхностью, поэтому рассмотрим планарное приближение с учетом увеличения площади, в результате чего расчетный профиль концентрации равен $2 \cdot 10^{17} \mathrm{~cm}^{-3}$, что близко к величине при удельном сопротивлении подложки $0.06 \Omega \cdot \mathrm{cm}\left(1 \cdot 10^{17} \mathrm{~cm}^{-3}\right)$. Расхождение может объясняться неравномерной глубиной травления SU-8, что приводит к увеличению вклада емкости $\mathrm{C}_{\mathrm{NW}}$ side из-за неполного обеднения SiNWs для $0.06 \Omega \cdot \mathrm{cm}$ в отличие от $0.2 \Omega \cdot \mathrm{cm}$ под верхней поверхностью волокон. При измерении образцов без SU-8 добавляется емкость $C_{\mathrm{NW} b o t}$, формируемая у основания между SiNWs на поверхности подложки. В результате емкость от массива SiNWs c барьером Шоттки равна

$$
C_{\mathrm{SB}}=C_{\mathrm{NW} t o p}+C_{\mathrm{NW} b o t}+C_{\mathrm{NW} \text { side }} .
$$

Значение $C_{\mathrm{NWbot}}$ будет посчитано с помощью приближения плоского конденсатора, поэтому для образцов без SU-8 сумма первых двух членов равна емкости плоского конденсатора под металлическим контактом с $S_{M e}$. $C_{\mathrm{NW} \text { side }}$ состоит из емкости одного цилиндрического $\mathrm{SiNW}$, умноженного на их количество $N_{\mathrm{NW}}$. К полученным SiNWs применима формула емкости цилиндра с двумя обкладками, где толщина ОПЗ $W$ равна разности радиусов обкладок:

$$
C_{\mathrm{NW} \text { side }}=\frac{2 \pi \varepsilon \varepsilon_{0} l_{\mathrm{NW}}}{\ln \frac{R_{\mathrm{NW}}}{R_{\mathrm{NW}}-W}} .
$$

Здесь $l_{\mathrm{NW}}$ - высота SiNWs, $\varepsilon_{0}$ - электрическая постоянная, $\varepsilon-$ относительная диэлектрическая проницаемость. Поскольку в верхней части SiNWs есть обеднение из-за $C_{\mathrm{NW} \text { top }}$, при расчете емкости массива SiNWs с помощью (2) в числителе формулы (3) нужно написать $l_{\mathrm{NW}}-W$. Если $W$ меньше $R_{\mathrm{NW}}$ формула расчета емкости массива $\mathrm{SiNWs}$ имеет вид

$$
C_{\mathrm{SB}}=\frac{\varepsilon \varepsilon_{0} S_{\mathrm{NW} t o p}}{W}+\frac{\varepsilon \varepsilon_{0}\left(S_{M e}-S_{\mathrm{NW} t o p}\right)}{W}+\frac{2 \pi \varepsilon \varepsilon_{0}\left(l_{\mathrm{NW}}-W\right)}{\ln \frac{R_{\mathrm{NW}}}{R_{\mathrm{NW}}-W}} .
$$

Таким образом, полученное из геометрических соображений уравнение является трансцендентным и может быть решено численно для $W$ в случае образцов без SU-8. В результате была получена зависимость толщины $W$ от приложенного напряжения смещения $V_{a}$, что позволило точно посчитать вклады от емкости боковой поверхности и планарной поверхности на массиве SiNWs. Поскольку вклад в емкость от боковой поверхности для исследуемых структур в 4-5 раза больше, чем от планарной емкости, был рассчитан профиль концентрации свободных носителей заряда вдоль радиуса волокна из уравнения потенциала, рассчитанного в цилиндрических координатах:

$$
\begin{aligned}
V_{a} & =-V_{b i}-\frac{q N_{d}}{\varepsilon \varepsilon_{0}}\left[\frac{\left(R_{\mathrm{NW}}-W\right)^{2}}{2} \ln \left(\frac{R_{\mathrm{NW}}}{R_{\mathrm{NW}}-W}\right)\right. \\
& \left.-\frac{R_{\mathrm{NW}}^{2}}{4}+\frac{\left(R_{\mathrm{NW}}-W\right)^{2}}{4}\right],
\end{aligned}
$$

где $V_{b i}$ - встроенный потенциал на границе $\mathrm{Au} / n-\mathrm{Si}$. В подложке с $0.06 \Omega \cdot \mathrm{cm}$ толщина ОПЗ изменяется от 90 до $195 \mathrm{~nm}$, т.е. она в 3 раза меньше $R_{\mathrm{NW}}=600 \mathrm{~nm}$, профиль концентрации практически постоянен и равен 
$1 \cdot 10^{17} \mathrm{~cm}^{-3}$ (см. вставку к рис. 3), что соответствует легированию подложки, а $V_{b i}=0.62 \mathrm{eV}$, что является характерным значением для барьера Шоттки $\mathrm{Au} / n-\mathrm{Si}$. $\mathrm{C}$ другой стороны, в подложке с $0.2 \Omega \cdot \mathrm{cm}$ толщина ОПЗ изменяется от $366 \mathrm{~nm}$ при $0 \mathrm{~V}$ до $576 \mathrm{~nm}$ при $-1 \mathrm{~V}$ и $734 \mathrm{~nm}$ при $-2 \mathrm{~V}$, а $R_{N W}=850 \mathrm{~nm}$. Это приводит к неравномерному профилю концентрации, что, видимо, вызвано недостаточной применимостью формулы (4) для такого соотношения толщин. Однако для экспериментальных данных, полученных в диапазоне от 0 до $-1 \mathrm{~V}$, профиль концентрации был рассчитан как $1.1 \cdot 10^{16} \mathrm{~cm}^{-3}$, что совпадает с параметром подложки, a $V_{b i}=0.76 \mathrm{eV}$.

Таким образом, в работе исследованы массивы кремниевых вертикально ориентированных волокон, полученных методом криогенного травления. Продемонстрировано, что напыление золота позволяет сформировать диод Шоттки с коэффициентом идеальности 1.1-1.3 и высотой барьера $0.6-0.7 \mathrm{eV}$. Показана применимость модели анализа вольт-фарадных характеристик таких массивов волокон с учетом вклада от всей поверхности структуры по их геометрическим размерам. Это позволяет рассчитать профиль концентрации не в отдельном волокне, а в их массиве, что критически важно для последующей их диагностики более сложными методами, такими как нестационарная спектроскопия глубоких уровней и спектроскопия адмиттанса.

\section{Финансирование работы}

Представленное исследование выполнено за счет гранта Российского научного фонда (проект № 19-7900338).

\section{Конфликт интересов}

Авторы заявляют, что у них нет конфликта интересов.

\section{Список литературы}

[1] K. Yoshikawa, W. Yoshida, T. Irie, H. Kawasaki, K. Konishi, H. Ishibashi, T. Asatani, D. Adachi, M. Kanematsu, H. Uzu, K. Yamamoto, Solar Energy Mater. Solar Cells, 173, 37 (2017). DOI: 10.1016/j.solmat.2017.06.024

[2] E.A. Vyacheslavova, I.A. Morozov, A.S. Gudovskikh, A.V. Uvarov, A.I. Baranov, D.A. Kudryashov, J. Phys.: Conf. Ser., 1695 (1), 012085 (2020). DOI: $10.1088 / 1742-6596 / 1695 / 1 / 012085$

[3] K. Sato, A. Castaldini, N. Fukata, A. Cavallini, Nano Lett., 12 (6), 3012 (2012). DOI: 10.1021/n1300802x

[4] G. Venturi, A. Castaldini, A. Schleusener, V. Sivakov, A. Cavallini, Nanotechnology, 26 (19), 195705 (2015). DOI: $10.1088 / 0957-4484 / 26 / 19 / 195705$

[5] R. Dussart, T. Tillocher, P. Lefaucheux, M. Boufnichel, J. Phys. D.: Appl. Phys., 47 (12), 123001 (2014).

DOI: $10.1088 / 0022-3727 / 47 / 12 / 123001$
[6] A. Smyrnakis, E. Almpanis, V. Constantoudis, N. Papanikolaou, E. Gogolides, Nanotechnology, 26 (8), 085301 (2015). DOI: 10.1088/0957-4484/26/8/085301

[7] I.A. Morozov, A.S. Gudovskikh, A.V. Uvarov, A.I. Baranov, V. Sivakov, D.A. Kudryashov, Phys. Status Solidi A, 217 (4), 1900535 (2020). DOI: 10.1002/pssa.201900535

[8] A.I. Baranov, D.A. Kudryashov, L.N. Dvoretckaia, I.A. Morozov, A.V. Uvarov, E.A. Vyacheslavova, K.Yu. Shugurov, A.S. Gudovskih, J. Phys.: Conf. Ser., 1695 (1), 012089 (2020). DOI: 10.1088/1742-6596/1695/1/012089

[9] A.I. Baranov, D.A. Kudryashov, I.A. Morozov, A.V. Uvarov, K.Yu. Shugurov, A.S. Gudovskih, J. Phys.: Conf. Ser., 1697 (1), 012060 (2020). DOI: 10.1088/1742-6596/1697/1/012060

[10] E.C. Garnett, Y. Tseng, D. Khanal, J. Wu, J. Bokor, P. Yang, Nature Nanotechnol., 4 (5), 311 (2009). DOI: $10.1038 /$ nnano.2009.43

[11] Y. Calahorra, D. Ritter, J. Appl. Phys., 114 (12), 124310 (2013). DOI: $10.1063 / 1.4823517$

[12] Y. Calahorra, E. Yalon, D. Ritter, J. Appl. Phys., 117 (3), 034308 (2015). DOI: 10.1063/1.4906210 